\title{
LUT
}

University

\section{Motion Synchronization of Biaxial Linear Tooth Belt Drive System}

Parkkinen Jukka, Nevaranta Niko, Niemelä Markku, Lindh Tuomo, Pyrhönen Juha

This is a Final draft

version of a publication

published by IEEE

in 2018 IEEE 18th International Power Electronics and Motion Control Conference (PEMC)

DOI: $10.1109 /$ EPEPEMC.2018.8521994

Copyright of the original publication: (c) 2018 IEEE

Please cite the publication as follows:

Parkkinen, J., Nevaranta, N., Niemelä, M., Lindh, T., Pyrhönen, J. (2018). Motion Synchronization of Biaxial Linear Tooth Belt Drive System. 2018 IEEE 18th International Power Electronics and Motion Control Conference (PEMC). DOI: 10.1109/EPEPEMC.2018.8521994 


\title{
Motion Synchronization of Biaxial Linear Tooth Belt Drive System
}

\author{
Jukka Parkkinen, Niko Nevaranta, Markku Niemelä, Tuomo Lindh, and Juha Pyrhönen \\ Department of Electrical Engineering, \\ Lappeenranta University of Technology \\ Lappeenranta, Finland \\ Email: niko.nevaranta@lut.fi
}

\begin{abstract}
Many manufacturing processes depend on accurate multi-axis movements. Development of drive technology has replaced the need of mechanical couplings and cams in synchronized manufacturing operations. In this paper motion synchronization of a biaxial linear tooth-belt drive is studied and, especially, the effects of the data communication's speed between the control system components on the motion synchronization successfulness is analyzed.
\end{abstract}

Keywords-Master-slave control, motion control, motion synchronization, multi-axis

\section{INTRODUCTION}

Assembly, cutting and printing applications need often precise multi-axis motion operation. Accuracy and speed requirements govern the choice of suitable actuators. In many applications, the movement is linear. Linear movement can be achieved by using linear motor drives or by converting rotational movement to linear one with tooth belts, leadscrews or racks and pinions. Linear tooth belt drives offer low-cost solutions for linear movements with wide operating range and capability for high-speed use [1].

The main problem with linear tooth belt drives is positioning inaccuracy. Elastic tooth belt and gap between driving pulley and belt set the positioning and contouring accuracies at a level which is not suitable for most demanding cutting or assembly applications. Also the elasticity sets system's natural frequency low which limits the control bandwidth. Limitations and possibilities of the linear tooth belt drive in motion control applications are analyzed in [2] and [3]. In [4] and [5] a tooth belt drive's accuracy with sliding mode controller (SMC) is studied in a laser cutting application. A vibration controller to reduce the belt-drive uncertainties is proposed. In previous works only single axis linear tooth belt drive systems have been analyzed.

Movement synchronization of multiple axes is a key factor with many assembly systems [6], [7]. Nowadays, intelligent drive control has replaced the need of the mechanical coupling systems in motion synchronization and gives a possibility to vary the motion responses of the slave axis freely [8]. As a result, different control approaches: fixed parameter cross-coupling controllers in [9], [17], adaptive one [10] and sliding mode controller in [11], has been proposed to guarantee the synchronized motion in a masterslave control.

The development of synchronization approaches for industrial control systems has been under extensive development recently [12] and the motion control software of modern programmable logic controllers (PLCs) has been under continuous development. The objective of this paper is to analyze the performance limitations related to the standard synchronization approaches when a biaxial $\left(\mathrm{x}_{1}, \mathrm{x}_{2}\right)$ tooth belt drive system is controlled with a cascaded PID-based control law. Data transfer between different units is studied in details. Two different synchronization methods - the Master-Slave method and synchronous delivery of references to independent drives positioning the $\mathrm{x}_{1}, \mathrm{x}_{2}$-axes - are compared. It is proven that selected communication medium between axes control systems sets limitations to the synchronization performance with the master-slave system. The syncronization approaches are verified on an experimental test system.

\section{MOTION SYNCHRONIZATION}

In a classical master-slave synchronization method the slave axis is driven based on the actual position value of the master axis. With this method also the position error of the master axis affects the slave axis motion which can be either an advantage or a disadvantage in a motion synchronization task. If the master axis has an error during the motion also the slave axis reacts and tries to keep the same position value as the master. The slave side errors on the other hand will not have an effect on the master side.

Ideally, a master-slave configuration is designed so that both master and slave have the newest possible position data to use in control cycles, which are executed synchronously. This situation is presented in Fig. 1 a). Depending on the used system configuration the communication delay to transmit master's actual position as slave reference, $t_{\mathrm{tr}}$, can vary from zero to several milliseconds depending on communication medium and method between the master and slave systems. With the situation presented in Fig. 1 a) the transmitting time of the position data has to be short compared to the systems' cycle time. 

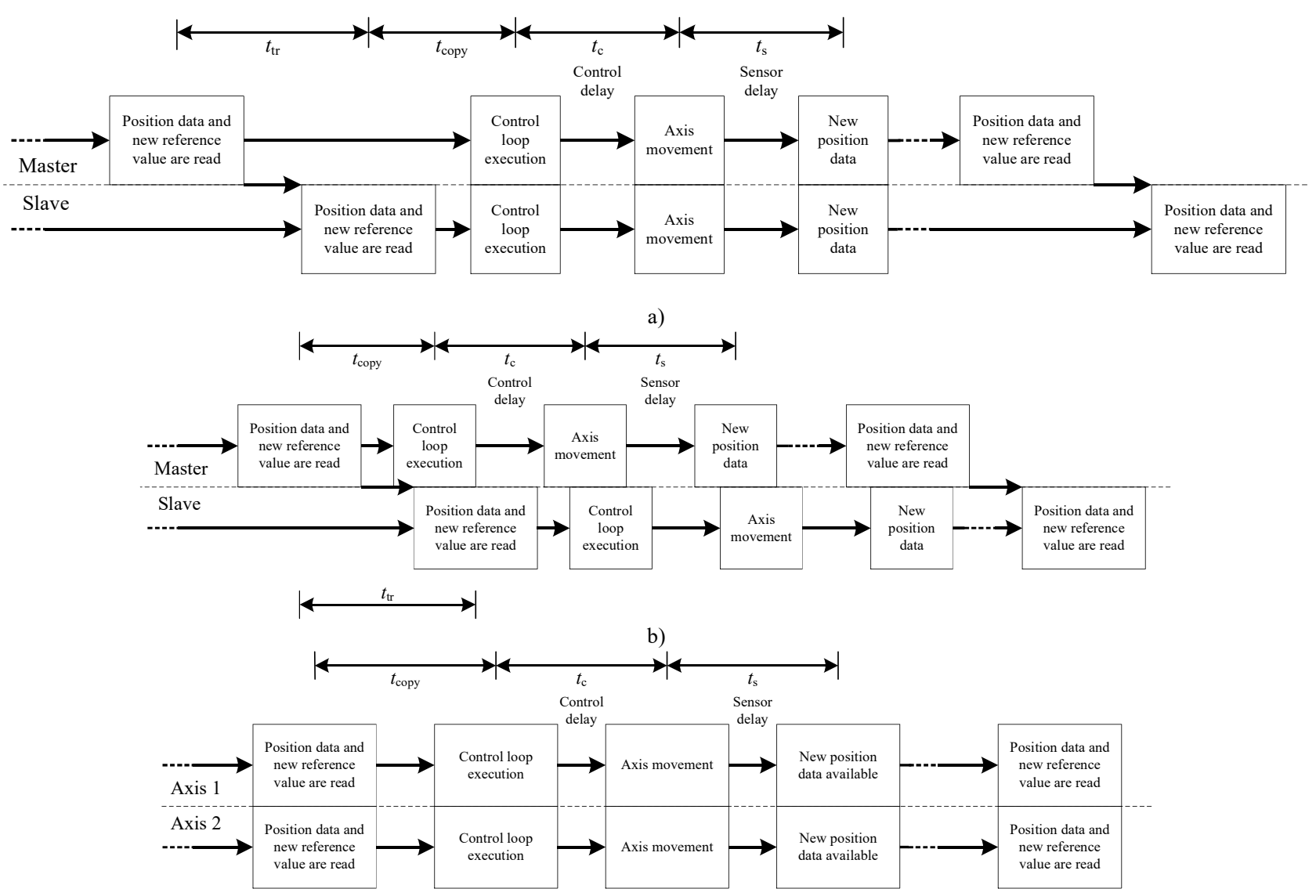

c)

Fig. 1. Different synchronization configurations: a) Ideal master-slave synchronization, b) Master-slave synchronization with fixed time levels and c) Synchronization using co-ordinate motions. Time value $t_{\text {tr }}$ presents the time needed to transmit position value from master to slave and $t_{\text {copy }}$ presents the delay needed to copy a new reference value for controllers.

With commercial drives the timings of the different operations in a drive are fixed and chained which changes the situation presented in Fig. 1 a) so that all actions on the slave side will happen after constant delay compared to the master side actions as presented in Fig. 1 b). In this case, the delay will appear as a position difference of between axes.

Transmitting time, $t_{\mathrm{tr}}$, is zero if the master position can be measured directly by the slave. That is possible if the system has an own encoder on the master axis which is read by the slave drive controller. Another fast transport channel for direct position data transfer can be created with position emulation or echoing sensor signal to multiple position sensor interfaces. Fieldbuses offer also a channel to transfer data between axes' controllers in many industrial multi-drive systems. Cyclic data transfer via fieldbus set limitations for fast communication between control systems because position data is first transferred to fieldbus master device and one communication cycle is, at least, needed before data is transmitted to the slave devices. The communication cycle time with fieldbus can vary from a few microseconds to several milliseconds depending on used fieldbus topology, number of devices and data payload on bus [13].

When both axes receive motion commands synchronously via the fieldbus no additional delays occur in the system.
Ideally, if the axes' dynamics and controller dynamics are equal there will be no position difference between the axes during or at the end of the motion. The advantage with such co-ordinate motions is that errors during motion do not have an influence on the second axis. Because of differences in the axes properties and loads some feedback knowledge of the other axis' situation may, however, be needed in some applications so that the user may have to add some extra error monitoring in the functionality in the system. Fig. $1 \mathrm{c}$ ) illustrates the actions of the system with the co-ordinate motions. The only critical point in the system is that both control systems receive the same reference value so early that there is enough time to process it before executing the control loops. Moreover, missing data on bus can also cause malfunction in the system.

\section{BIAXIAL SYSTEM UNDER STUDY}

The test setup for the biaxial system is a Cartesian manipulator illustrated in Fig. 2 a) where linear movements are gained by using linear tooth belt guides. To gain better loading capabilities on the moving axis multiple linear guides can be used. The traditional method to achieve synchronous movement between guides is to use only one servo motor and connecting both guides' drive-end pulleys with shaft [2]. 


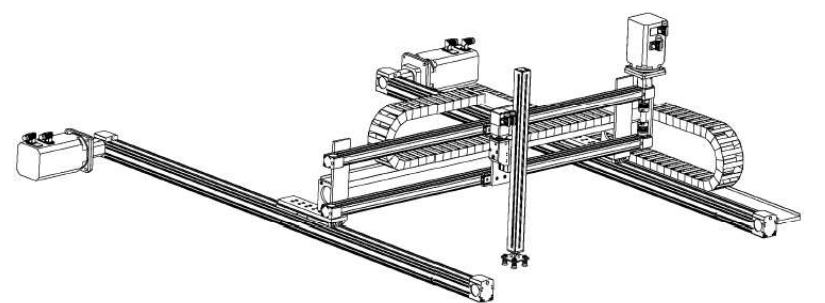

a)

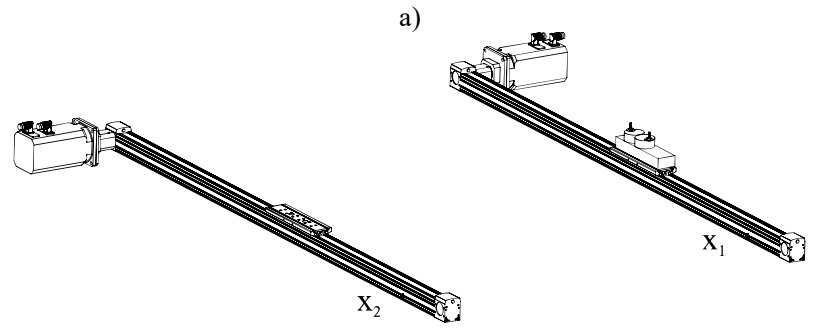

b)

Fig. 2. a) A Cartesian robot. b) Biaxial configuration under study created by using only the guides of $\mathrm{x}$-axis. Dynamics between guides can be changed by inserting additional load on the other guide.

Downside of the shaft comes with one more resonant frequency in the system [3]. Also the distance between two guides of the $\mathrm{x}$-axis is the operation range of the $\mathrm{y}$-axis which can be relatively big with some applications. The length of the connection shaft set limits for the maximum velocity on the axis and linear tooth-belt drive's full performance potential may not be achieved [14]. In this paper, the biaxial test setup is created by using only guides of $\mathrm{x}$-axis as illustrated in Fig. 2 b). Other axes are removed during tests so guides have no physical connection and dynamics between guides can be freely changed using external masses.

The controlling of the axes is carried out with frequency converter drives (ASCM1) which are equipped with commercial motion control software. An embedded PC with a Beckhoff's programmable logic controller (PLC) is used to create the position profiles, and communications between the PLC and the converters are carried out via synchronous EtherCAT fieldbus. The fieldbus is also used to synchronize drive operations. The block diagram of the system is presented in Fig. 3. The direct drive-to-drive communication illustrated in Fig. 3 is established between drives' position encoder interfaces for fast position data transfer from drive 1 to drive 2 with master-slave synchronization.

The converter controllers are cascaded position controllers with velocity feedforward. The position controllers are proportional $(\mathrm{P})$ controllers and the velocity controllers are PI-controllers. Communication between the PLC and the position controllers runs with a cycle time of $500 \mu \mathrm{s}$. The corresponding cycle times in the velocity controllers and drives' feedbacks are on $250 \mu$ s time-level. Both motors are equipped with multi-turn absolute encoders and the load carriers on the tooth belt guides have magnetic band increment linear encoders. The absolute multi-turn encoders' resolution is 8192 points per revolution and the linear encoders' resolution is $25 \mu \mathrm{m}$.

\section{A. $\quad$ Mathematical modeling of tooth belt drive}

The experimental system consists of two tooth belts, two carts, four pulleys and two motors as depicted in Fig. 2 b). Both guides are directly driven so no speed-reducing gear is applied in the system. A single tooth belt drive system ignoring the motor flexibility - can be considered as a springmass system because of the elasticity of the tooth belt as illustrated in Fig. 4. The modeling of the tooth belt drive can be found in [16].

The dynamics of the non-drive-end pulley can be neglected from the model to simplify the analysis [15], [17]-[19] of the system because the inertia at the non-drive-end is small compared to the system inertia caused by the drive-end and the load. Neglecting the non-drive-end creates a further reduced-order, but practically accurate enough system model which is illustrated in Fig. 5 a). Belt also has some damping constants $b_{\text {s }}$ and applied system model is presented in Fig. 5 b). Inertias of the drive-end are symbolized with $J_{\mathrm{s}}$ and the mass of the load with $m_{\mathrm{L}}$ in Fig. 5. Equations for the reducedorder system can be found in [19].

The equivalent spring constant $K(x)$ can be formed by replacing the three springs in Fig. 5 with just one spring. Spring constants $K_{2}(x)$ and $K_{3}$ are in series and parallel with the spring constant $K_{1}(x)$ which results in

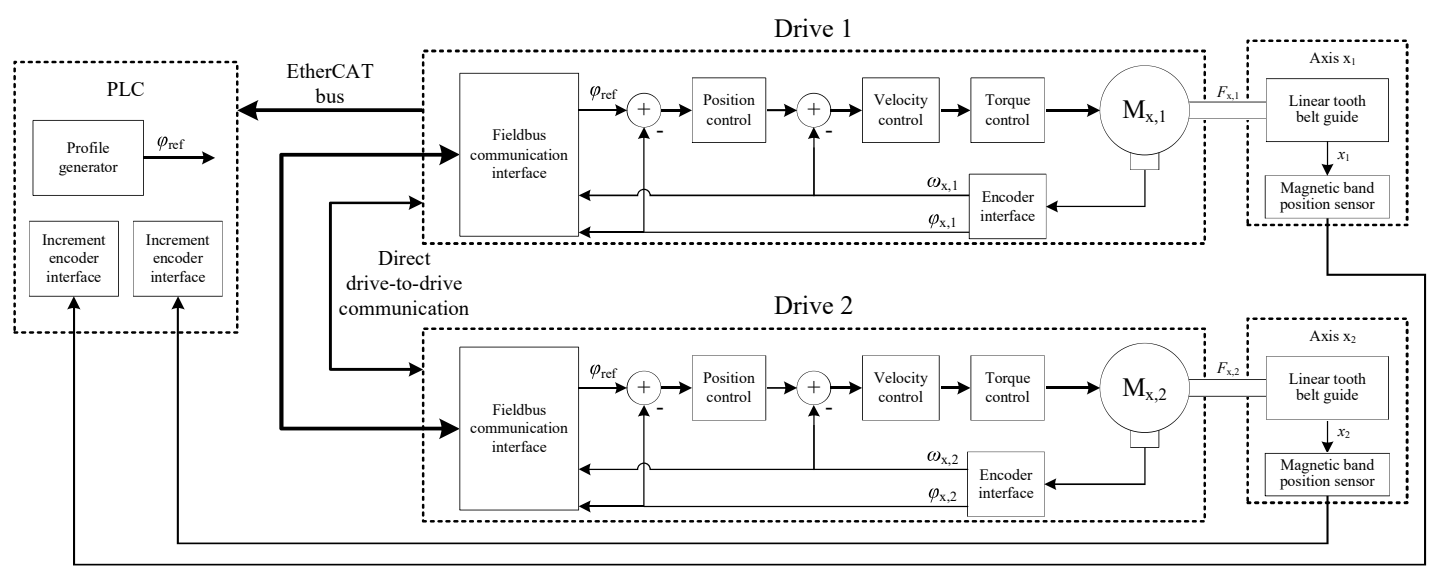

Fig. 3. Block diagram of the system, where $\varphi_{\text {ref }}$ is the position reference, the $\varphi_{\mathrm{x}, 1}$ and $\varphi_{\mathrm{x}, 2}$ are the measured positions and the $\omega_{\mathrm{x}, 1}$ and $\omega_{\mathrm{x}, 2}$ are the measured angular velocities. 


$$
K(x)=K_{1}(x)+\frac{1}{\frac{1}{K_{2}(x)}+\frac{1}{K_{3}}}=K_{1}(x)+\frac{K_{2}(x) K_{3}}{K_{2}(x)+K_{3}}
$$

Based on modeling discussed in [16], [17], [19] the system transfer function from torque to the angular position of the drive-end pulley without the friction terms is

$$
G(s)=\underbrace{\frac{1}{J_{S} m_{L} s}}_{\text {Rigid part }} \underbrace{\frac{m_{L} s^{2}+b_{S} s+K}{s^{2}+\frac{J_{S}+m_{L} r^{2}}{J_{S} m_{L}} b_{S} s+\frac{J_{S}+m_{L} r^{2}}{J_{s} m_{L}} K}}_{\text {Flexible part }}
$$

where $r$ is the radius of the belt pulley and $K$ the spring constant certain position $x$ based on (1). It has been shown that reduced-order system model represents the essential system dynamics in different operating points [16], [17] and can be used to design high-performance robust position control for tooth belt drives [17]. Thus, in this paper, Quantitative Feedback Theory (QFT) is applied to design position cascade controllers for both axes. The QFT design for a linear tooth belt drive is presented and analyzed in details in [16]. The same approach has been applied successfully for cascade motion control design in [20]. Some details about the controller design can be found in the Appendix.

With the QFT control design the parameter variation is noticed and suitable phase and gain margins are set to the system. Note that, the commercial motion control software gives the possibility to implement the designed cascaded controller directly to the software. Parameter variations considered in the control design are presented in Table I and the parameters of the controller designed are given in Table II. It is worth pointing out that the controller parameters for both axis are same and the design is robust for large parameter variation. Thus, in the experimental tests the mass of the cart can be freely changed within the limits expressed in Table I without losing robustness during the tests. Mechanical parameters and dimensions of the linear tooth belt guides under study of the guide are presented in Table III. Position dependent spring constants can be approximated

TABLE I

\begin{tabular}{|c|c|c|}
\hline Symbol & Parameter & Value \\
\hline$J_{\mathrm{S}}$ & Inertia & $0.0016-0.004 \mathrm{kgm}^{2}$ \\
\hline$m_{\mathrm{L}}$ & Load mass & $2.7-30 \mathrm{~kg}$ \\
\hline$K(x)$ & Spring constant & $4 \cdot 10^{5}-4 \cdot 10^{6} \mathrm{~N} / \mathrm{m}$ \\
\hline
\end{tabular}

PARAMETER VARIATIONS

TABLE II

DESIGNED CONTROLLER PARAMETERS*

\begin{tabular}{ccc}
\hline \hline Symbol & Quantity & Value \\
\hline$P_{\text {pos }}$ & Position controller gain & $551 / \mathrm{s}$ \\
$P_{\text {vel }}$ & Velocity controller gain & $1.12881 / \mathrm{s}$ \\
$T_{\mathrm{i}}$ & Velocity controller integration time & $0.0037 \mathrm{~s}$ \\
$P_{\mathrm{ffv}}$ & Velocity feedforward gain & 1 \\
\hline \hline \multicolumn{2}{c}{$*$ See [16] for details about the QFT-based controller tuning. }
\end{tabular}

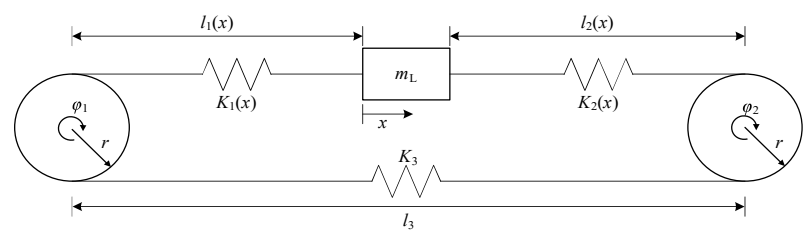

Fig. 4. Spring-mass model of a linear tooth belt drive ignoring the flexibility of the motor parts. $K_{1}, K_{2}$ and $K_{3}$ describe the spring constants of the belt lengths $l_{1}, l_{2}$ and $l_{3}, m_{\mathrm{L}}$ is the load mass and $\varphi_{1}$ and $\varphi_{2}$ the turning angles of the similar pulleys with radii $r$ and inertias $J_{\mathrm{p}}$.
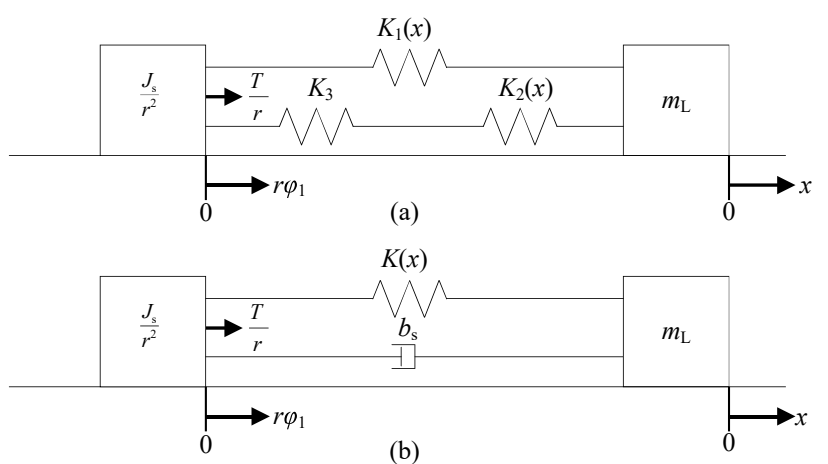

Fig. 5. System model. (a) Reduced-order model where non-drive end is neglected. (b) Belt damping applied in the system.

as shown in [2] using the dimensions of the Table III.

\section{EXPERIMENTAL RESULTS}

The synchronization methods illustrated in Fig. 1 are studied and compared with experimental measurements. Synchronization of motion is measured with linear contour. Both - motor shaft feedback value difference scaled as linear error and cart position error - are presented. The master-slave synchronization is measured using two different communica tion channels; direct and indirect, to show how much communication delay has an impact on position difference between axes.

The reference acceleration, the velocity and the position profiles used in the experiments are shown in Fig. 6. The position profile generator is in PLC and position reference values are transmitted cyclically via fieldbus to the master drive in master-slave topology and to both drives with coordinate motions system. To avoid unnecessary vibrations on belt the second derivative of the velocity, known as jerk, is set to $250 \mathrm{~m} / \mathrm{s}^{3}$ in the reference profile. Dynamic difference between axes is created by adding a $24 \mathrm{~kg}$ load mass on $\mathrm{x}_{1}$ axis. The $\mathrm{x}_{2}$-axis guide is empty. With high extra load on $\mathrm{x}_{1}$ axis guide the belt stretching is much greater than with the

TABLE III

GUIDE PARAMETERS

\begin{tabular}{ccc}
\hline \hline Symbol & Quantity & Value \\
\hline$J_{\mathrm{p}}$ & Inertia of the pulley & $9.9 \cdot 10^{-6} \mathrm{kgm}^{2}$ \\
$r$ & Effective radius of the pulley & $19.89 \mathrm{~mm}$ \\
$l_{0}$ & Zero point length of the belt & $0.25 \mathrm{~m}$ \\
$l_{3}$ & Distance between pulleys & $2.1 \mathrm{~m}$ \\
$l_{\mathrm{c}}$ & Cart length & $0.44 \mathrm{~m}$ \\
$m c$ & Cart mass & $2.7 \mathrm{~kg}$ \\
\hline \hline
\end{tabular}


empty $\mathrm{x}_{2}$-axis. Position error caused by stretching cannot, naturally, be measured from the motor feedback signal.

\section{A. Master-slave method with direct communication}

First, the master-slave synchronization method illustrated in Fig. 1 a) is studied with experimental measurements. Direct communication between axes is created with test setup by emulating position data from the master motor feedback directly to the slave drive encoder interface. The control loops of the drives are synchronized via fieldbus. Position difference between driving motor positions and load carts is presented in Fig. 7 a). Difference between motor positions is scaled as linear to illustrate belt stretching in the system.

It can be noticed in Fig. 7 a) that spikes between motor feedback values occurs at every accelerations and decelerations which shows how well tooth belt drive can follow reference at no-load conditions. The difference between motor feedback position difference and cart position difference is caused by stretching of the belt. The position error of the both axes is presented in Fig. 8 a). More heavily loaded axis $\mathrm{x}_{1}$ has poorer dynamics, as expected, and error over the profile is bigger than no-loaded axis $\mathrm{x}_{2}$. Especially accelerations and decelerations cause big error at master axis $\mathrm{x}_{1}$.

\section{B. Master-slave method with indirect communication}

The second synchronization method studied is illustrated in Fig. 1 b). Now indirect communication setup is considered where the master's motor feedback value is transferred as slave reference via fieldbus. It is worth remarking that, the cyclic fieldbus communication set limits for slave to achieve current master axis position. The delay caused by fieldbus communication is two communication cycles, thus in this case $1 \mathrm{~ms}$. This causes position difference between axes to be much greater as shown in Fig. 7 b) than in the situation presented in Fig. 7 a) where the slave does not have to wait position data of the master. This error makes the master-slave method unusable in applications where the slave response has to be immediate to the master's position variation like the situation is with accurate printing and cutting applications.

In Fig. 8 b) is presented position errors for each axis measured from motor feedback which shows that the position error seen by the controllers is the same as was in previous measurement in Fig. 8 a).

TABLE IV

INTEGRATED ABSOLUTE ERROR (IAE) AND MAXIMUM ERROR VALUE OF POSITION DIFFERENCE BETWEEN AXES.

\begin{tabular}{cccc}
\hline \hline & $\begin{array}{c}\text { Direct } \\
\text { master-slave }\end{array}$ & $\begin{array}{c}\text { Indirect } \\
\text { master-slave }\end{array}$ & $\begin{array}{c}\text { Synchronized } \\
\text { motions }\end{array}$ \\
\hline$\Delta_{\text {rot,IAE }}[\mathrm{mms}]$ & 0.265 & 2.528 & 0.706 \\
$\Delta_{\text {lin,IAE }}[\mathrm{mms}]$ & 0.479 & 3.012 & 1.004 \\
$\Delta_{\text {rot,max }}[\mathrm{mm}]$ & 0.639 & 3.031 & 1.698 \\
$\Delta_{\text {lin,max }}[\mathrm{mm}]$ & 0.963 & 3.839 & 2.573 \\
\hline \hline
\end{tabular}
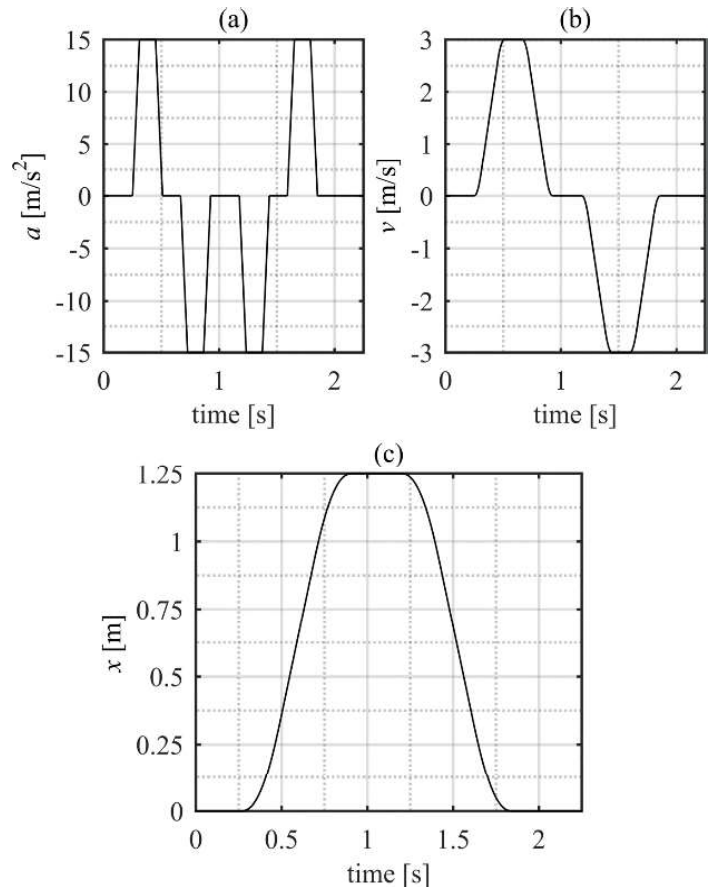

Fig. 6. (a) acceleration, (b) velocity, and (c) position reference values as a function of time.

\section{C. $\quad$ System with co-ordinate motions}

By considering the co-ordinate synchronization method in Fig. 1 c) the drives' time levels are synchronized with fieldbus master's time levels and both drives receive same position reference values from the PLC. The position difference between axes in the system with co-ordinate motions is now caused by the difference in axes dynamics. Fig. 7 c) shows how no-load $x_{2}$-axis has a better response to the accelerations and decelerations of the reference profile than $\mathrm{x}_{1}$-axis with high mass. Stretching phenomenon is also clearly visible by comparing the position differences of the motor feedbacks and carts, especially, when carts are closer to the non-drive end.

Furthermore, when driven synchronously with same position references no-load axis $\mathrm{x}_{2}$ shows how well axis can response with designed reference profile in Fig. $8 \mathrm{c}$ ). With previous master-slave situations reference profile for axis $\mathrm{x}_{2}$ is affected with all position errors of the master axis. Again it can be noticed that the position errors are almost similar with the other approaches shown in Fig. 8 a) and b), as expected.

TABLE V

INTEGRATED ABSOLUTE ERROR (IAE) AND MAXIMUM ERROR VALUE OF DRIVE MOTORS SCALED TO LINEAR.

\begin{tabular}{cccc}
\hline \hline & $\begin{array}{c}\text { Direct } \\
\text { master-slave }\end{array}$ & $\begin{array}{c}\text { Indirect } \\
\text { master-slave }\end{array}$ & $\begin{array}{c}\text { Synchronized } \\
\text { motions }\end{array}$ \\
\hline$e_{\mathrm{x} 1, \mathrm{IAE}}[\mathrm{mms}]$ & 0.942 & 0.938 & 0.937 \\
$e_{\mathrm{x} 2 \mathrm{IAE}}[\mathrm{mms}]$ & 0.265 & 0.264 & 0.263 \\
$e_{\mathrm{x} 1, \max }[\mathrm{mm}]$ & 2.212 & 2.186 & 2.182 \\
$e_{\mathrm{x} 2, \max }[\mathrm{mm}]$ & 0.639 & 0.622 & 0.512 \\
\hline \hline
\end{tabular}




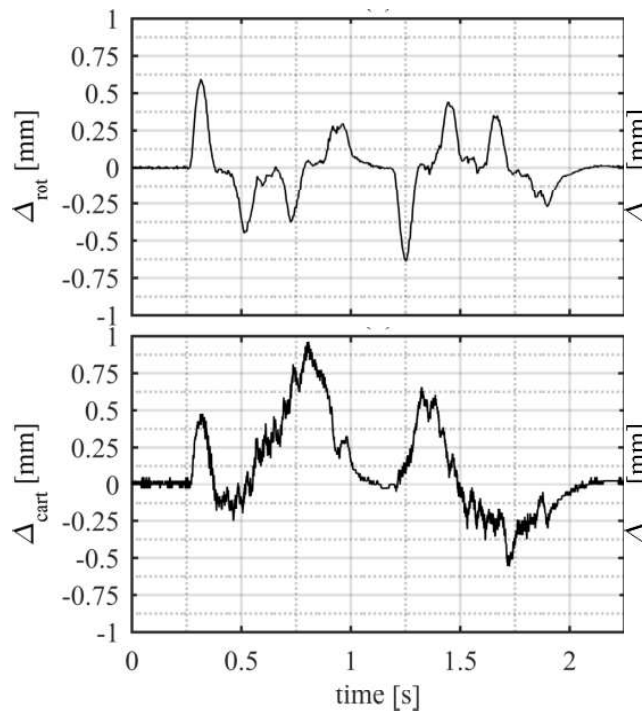

a)

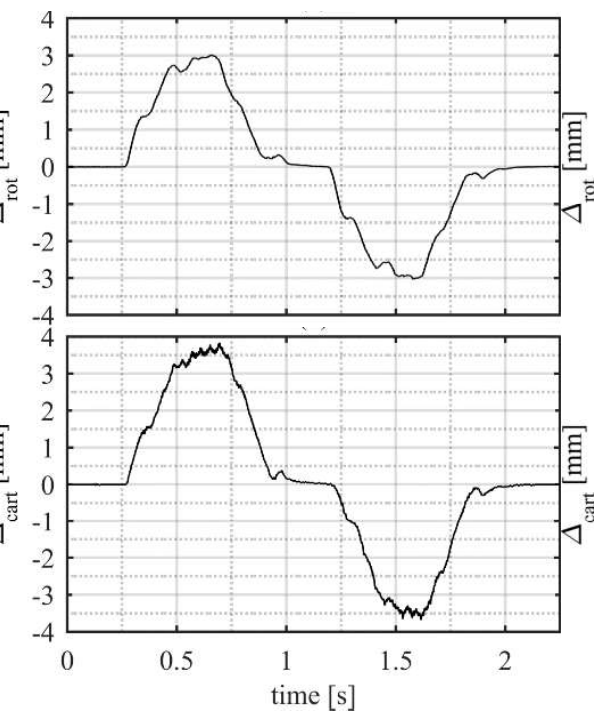

b)

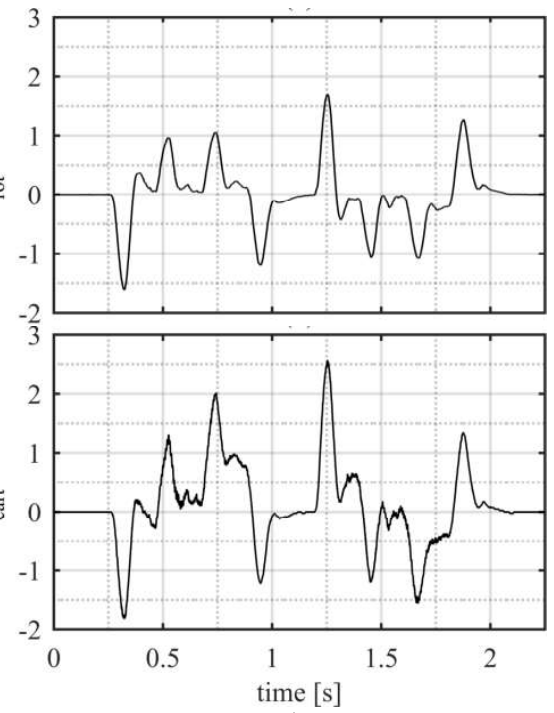

c)

Fig. 7. Measured position difference of axes $x_{1}$ and $x_{2}$ a) with the master-slave topology where the slave uses directly master's motor feedback signal as reference, b) where the slave uses master's motor feedback signal as reference via fieldbus, and c) with co-ordinate motions system. The figures above presents the scaled difference of axes' motor shafts' feedback values and figures below shows the position difference between the load carts.'

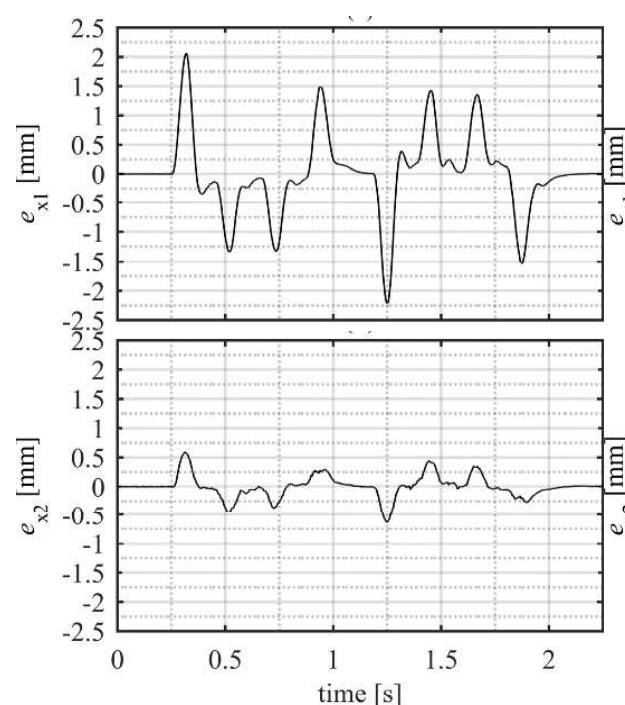

a)

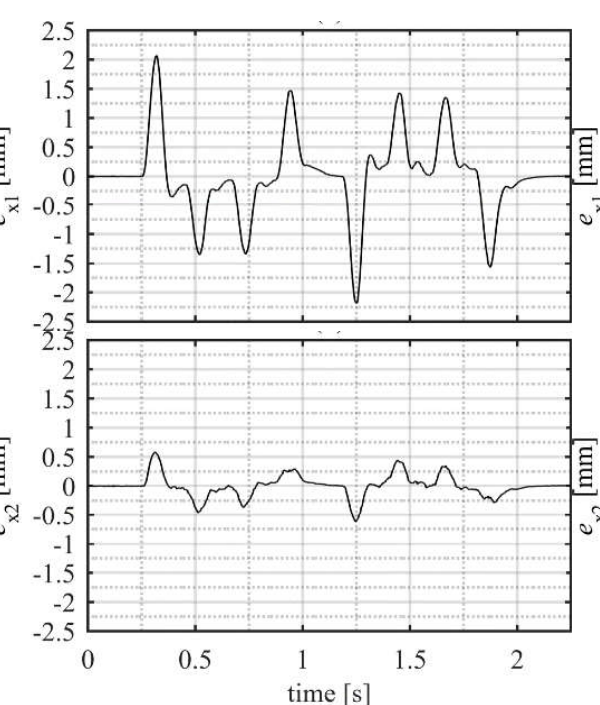

b)

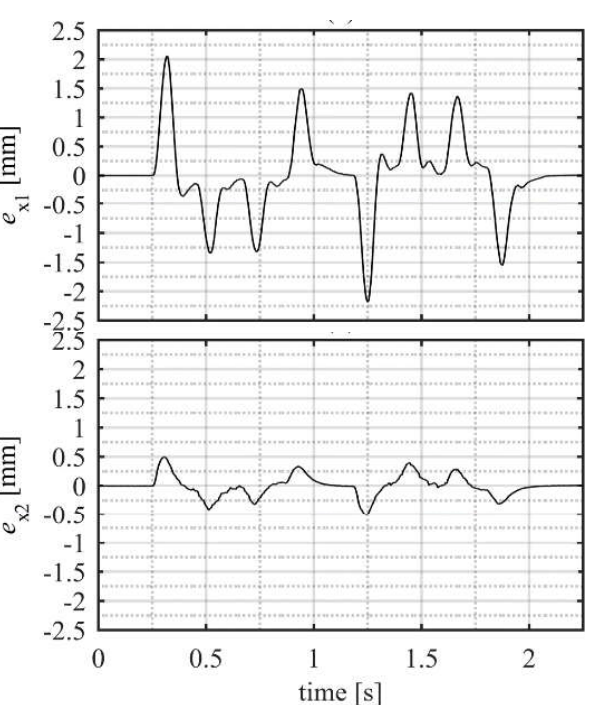

c)

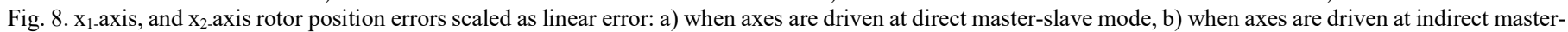
slave mode and $\mathrm{c}$ ) when axes are driven synchronized motion profiles

\section{Numerical analysis}

Numerical results of previous measurements are shown in Tables IV and V. Results of these tables show the maximum error values of position difference between axes and single axis maximum drive motor position errors. Also the integral of the absolute error (IAE) of previous measurements are calculated. The values in Table V shows that the IAE and the maximum position erros are almost same that can be also noticed when comparing the Fig. 8 a), b) and c).

\section{CONCLUSION}

In this paper, the challenges of the communication channel and its effects on the multi-axis system accuracy are presented. Even though the accuracy of the tooth belt drive itself is in millimeter class the delay in communication between master and slave creates position difference between axes which can be several millimeters. This communication delay makes the master-slave method impracticable for solutions where slave has to follow closely the master's position, which is needed, for example, in high accurate printing application. Accuracy of the biaxial tooth belt drive system with co-ordinate motions cannot achieve as good results as master-slave synchronization when a dynamic difference is this significant between axes. For better performance of the system with co-ordinate motions adaptive controllers can improve single-axis accuracy and at the same time the difference between axes is decreased. Also different 
coupled controllers can improve the motion synchronization of the system.

The experimental results in this paper have been obtained by using electrical drives with commercial motion control software. Thus, the delays of the control executions, communications and feedback data acquisition cannot be analyzed thoroughly. Nevertheless, different motion synchronization methods can be compared by means of linear position error between axes and the influence of delay between different methods can be seen. Future study will focus on same research problem, but the commercial drives of the experimental setup will be replaced with FPGA based frequency converters that gives the possibility to analyze and change the delays of the communication and control loops.

\section{APPENDIX}

The QFT controller design in frequency domain is based on the determination of the robust margins for the sensitivity and complementary sensitivity functions

$$
\begin{aligned}
& \left|\frac{L(j \omega)}{1+L(j \omega)}\right|<W_{1}=M_{T}, \\
& \left|\frac{1}{1+L(j \omega)}\right|<W_{2}(j \omega)=\left|\frac{\left(\frac{j \omega}{M_{S}^{1 / n}}+\omega_{b}\right)^{n}}{\left(j \omega+\omega_{b} A^{1 / n}\right)^{n}}\right|,
\end{aligned}
$$

where $L$ is the loop transfer function, $M_{\mathrm{T}}$ and $M_{\mathrm{S}}$ robust margins, $\omega_{\mathrm{b}}$ desired bandwidth, $A$ is the attenuation at zero frequency, and $n$ is the order of the sensitivity function. In the design, $\mathrm{A}=0.0001, \omega_{\mathrm{b} \text {,pos }}=8.7 \mathrm{~Hz}$ and $\omega_{\mathrm{b} \text {,vel }}=17 \mathrm{~Hz}, M_{\mathrm{s} \text {, vel }}$ $=2 M_{\text {T,vel }}=1.05$. See details about the QFT-based control design in [16]. It is noted that, in the controller design, the delay $\tau_{\mathrm{d}}=390 \mu$ s of the transmitting medium is modeled with a Pade approximation and the torque control dynamics is included to (2) as a first order system with a fixed time constant value $\tau_{\mathrm{e}}=0.00018 \mathrm{~s}$. The QFT template of uncertain plant is generated with the Pade approximation and (2) using the values in Table I. The performance of the controller is evaluated at eight different discrete points between 1-2000 $\mathrm{rad} / \mathrm{s}$. The design also takes into consideration performance specification for control effort for sensor noise,

$$
\left|\frac{C H}{1+P C H}\right|<W_{5}(j \omega)
$$

where $H$ denotes the sensor, $C$ controller and $P$ the plant dynamics, respectively. A pre-filter is not considered in the design, thus the tracking performance function is not taken into account.

\section{REFERENCES}

[1] R. Haus, "Converting Rotary Motion to Linear Motion," Journal of Power Conversion \& Intelligent Motion, vol. 22 n. 11, 1996, pp. 7275 .
[2] M. Jokinen, S.E. Saarakkala, M. Niemelä, R. Pöllänen, J. Pyrhönen, "Physical Drawbacks of Linear High-Speed Tooth Belt Drives," SPEEDAM, Int. Symp. of Power Electronics, Electrical Drives, Automation and Motion, June 11-13, 2008, Ischia, Italy.

[3] S.E. Saarakkala, M.E. Haapala, M. Jokinen, M. Niemelä, R. Pöllänen, J. J. Pyrhönen, "Performance, Limitations, and Control of a HighSpeed Tooth Belt Drive in a Motion Control Application," IEEE EUROCON '09, May 18-23, 2009, Saint-Petersburg, Russia.

[4] A. Hace, K. Jezernik, M. Terbuc, "Robust motion control algorithm for belt-driven servomechanism," IEEE Int. Symp. on Industrial Electronics, ISIE '99, July 12-16, 1999, Bled, Slovenia.

[5] A. Hace, K. Jezernik, A. Šabanović, "A New Robust Position Control Algorithm for a Linear Belt-Drive," IEEE Int. Conf. of Mechatronics, ICM '04, June 3-5, 2004, Istanbul, Turkey.

[6] E. Kyrkjebø and K. Y. Pettersen, "Operational space synchronization of two robot manipulators through a virtual velocity estimate," Modeling, Identification and Control, vol. 29 n. 2, 2008, pp. 59-66.

[7] E. Kyrkjebø, "Dynamic and kinematic observers for output coordination control of Euler-Lagrange systems: A comparison and applications," Modeling, Identification and Control, vol. 35 no. 2, 2015, pp. 103-118.

[8] E. Kiel, Drive Solutions: Mechatronics for Production and Logistics (Springer-Verlag Berlin Heidelberg, 2008)

[9] D. Yu, Q. Hu, and f. Zhao, "Syncronous motion control of biaxial driving system with linear servo motors," in Proc. of the IEEE Int. Conf. on Automation and Logistics, Shenyang, China, Aug. 2009, pp. 638-641.

[10] X. Kong, C., Chen, and Bangchun Wen, "Composite synchronization of three eccentric rotors driven by induction motors in a vibrating system," Mechanical systems and signal processing, vol. 102, 2018, pp. $158-179$.

[11] B. Sencer, T. Mori, and E. Shamoto, "Design and application of a sliding mode controller for accurate motion synchronization of dual servo systems," Contr. Eng. Practice, vol. 21, 2013, pp. 1519-1530.

[12] J. Molano, A. Lahrache, R. Rubini, and M. Cocconcelli, "A new method for motion syncronization among multivendor's programmable controllers," Measurement, May 2018. doi: https://doi.org/10.1016/j.measurement.2018.05.050.

[13] G. Prytz, "A performance analysis of EtherCAT and PROFINET IRT," IEEE Int. Conf. on Emerging Technologies and Factory Autom., ETFA, September 15-18, 2008, Hamburg, Germany.

[14] Festo, Accessories for electrical positioning systems, Festo technical documentation, 2010.

[15] A. Hace, K. Jezernik, A. Šabanović, "SMC with disturbance observer for a linear belt drive," IEEE Trans. on Ind. Electron, vol. 54 n. 6, December 2007, pp. 3402-3412.

[16] M. Jokinen, Centralized Motion Control of a Linear Tooth Belt Drive: Analysis of the Performance and Limitations, Ph.D. dissertation, Dept. Elect. Eng., Lappeenranta Univ. of Tech., Lappeenranta, Finland, 2010.

[17] J. Parkkinen, M. Jokinen, M. Niemelä, T. Lindh, and J. Pyrhönen, "Motion synchronization of two linear tooth belt drives using crosscoupled controller," in Proc. EPE Conf., Lille, France, Sep. 2013, pp. $1-7$.

[18] N. Nevaranta, J. Parkkinen, T. Lindh, M. Niemelä, O. Pyrhönen, and J. Pyrhönen, "Online Estimation of Linear Tooth Belt Drive System Parameters," IEEE Trans. on Ind. Electron., vol. 62, n. 11, Nov. 2015, pp. 7214-7223.

[19] N. Nevaranta, J. Parkkinen, M. Niemelä, T. Lindh, O. Pyrhönen, and J. Pyrhönen, "Recursive identification of linear tooth belt-drive system," in Proc. EPE Conf., Lappeenranta, Finland, Aug. 2014, pp. 1-8.

[20] Z. Liu, F. Luo, and M. Rashid, "QFT-Based robust and precision motion control system for a high speed direct-drive XY table positioning mechanism," in $38^{\text {th }}$ IAS annual meeting., UT, USA, Oct. 2003, pp. 293-300 